\title{
EP-125
}

\section{Squamous cell carcinoma of the gallbladder: A case report}

\author{
Ji-Hye KIM, Hye-Sung JO, Young-Dong YU, Dong-Sik KIM*
}

Department of Surgery, Korea University College of Medicine, Seoul, Korea

Introduction: Squamous cell carcinoma is a rare histopathologic subtype of gallbladder cancer. Few studies have reported its tendency for liver infiltration and poor prognosis compared to adenocarcinoma. We present a case of squamous cell carcinoma of the gallbladder.

Methods: A 70-year-old female patient had sustained right flank pain and weight loss of $10 \mathrm{~kg}$ in 4 months. On computed tomography (CT) scan, either intrahepatic cholangiocarcinoma with direct invasion to gall bladder or gallbladder cancer with direct invasion to liver segments 4 and 5 was suspected. Serum tumor markers were within normal ranges. She had a normal liver function, and no distant metastasis was observed.

Results: We performed anatomical S4/5 segmentectomy with cholecystectomy en bloc. The frozen section of the cystic duct margin was negative for malignancy. The operation time was $180 \mathrm{~min}$, and the estimated blood loss was $650 \mathrm{~mL}$. Final histopathological analysis revealed a well-differentiated squamous cell carcinoma with a focal adenocarcinoma component (<5\%), and tumor stage was T3. All surgical resection margins were confirmed to be negative for tumor cell. She was discharged without any complications at POD 8 . However, CT scan and positron emission tomography-CT performed 2 months after operation indicated intraabdominal seeding metastases. Thus, the patient planned for chemotherapy.

Conclusions: Squamous cell carcinoma of the gallbladder had similar preoperative characteristics with adenocarcinoma. Despite curative resection with a negative margin, it had aggressive manifestation. 